of hypothalamic hyperphagia is also seen in the normal hibernator and is adaptive in this type of animal.

Continuous recording of food and water intake, measurement of meal and draught sizes and the intervals between ingestion have been given fresh impetus by the work of Le Magnen of Paris. One finding that may have wide implications is the discovery that as a result of a single exposure, animals can learn to avoid substances which they have eaten and which lead after a considerable delay to illness. This is a reminder of how animals learn what foods to eat in order to relieve such things as vitamin deficiencies.

\section{POPULATION DYNAMICS}

\section{Lemmings Come and 60}

LEMmINGS, the small short-tailed rodents which inhabit the northern tundras, have three claims to fame. One species, the Norway lemming, undergoes suicidal migrations into the sea when population density outstrips food supplies. Another species, the collared lemming, is the only small rodent which turns white in the winter. Then the North American brown lemming, although it does not share the suicidal behaviour of the Norway lemming, manifests perhaps the most spectacular cyclic fluctuation in population known. These animals now have yet another distinction. According to Dr D. A. Mullen of the University of California, in an article on reproduction by brown lemmings (Lemmus trimucronatus) now published by the University of California Press (Publications in Zoology, 85, 1; 1968), the social stress hypothesis of population control, which seeks to explain fluctuations in populations in terms of an inverse relationship between population density and reproductive success, does not apply to the brown lemming in the wild. Dr Mullen has spent six years studying the brown lemming near Barrow in Alaska and has concluded that environmental factors, particularly temperature, regulate lemming populations. Population density seems to have no significant effect on fecundity.

Brown lemmings breed in two distinct periods, one in the summer and a less important one in winter. Females, at least during the summer, remain in continuous oestrus until they become pregnant. Copulation induces ovulation. The gestation period is 20 days, summer litters average between six and seven and puberty is reached within three weeks, all of which explains the enormous reproductive potential of the species, and, no doubt, its ability to survive the severe environment of the tundras.

During the six years 1960-65, Dr Mullen observed no significant varietions in male reproduction, except that juvenile male maturation was retarded in short breeding seasons. There was no evidence of a decline of litter size at the time of population crash of the kind postulated by proponents of the social stress theory as one of the chief causes of population decline. Indeed, reproduction was more successful among lemmings from large than from low populations, and the only consistent modifier of reproduction seems to be the length of the breeding season, which is in turn related to temperature and not to population density. Thus the breeding seasons of 1961 and 1963 were almost identical, but the population in 1963 was more than a hundred times greater than in 1961 .
The fact that the social stress theory does not apply to lemmings is not especially surprising. Dr Mullen points out that a variation of breeding season of a few days, which would be unimportant for temperate animals, is vitally important to species in severe environments such as the tundras. He believes that if lem. mings were subject to the dual control of climate and population density, the species would quickly reach extinction. The attunement of summer reproduction to climate might thus have been predicted, but it is difficult to explain why there is no sign of temperature regulation in winter, when the species has a secondary phase of reproduction at temperatures well below those which inhibit reproduction in the summer. Presumably some other factors trigger off the winter breeding.

\section{GENETICS}

\section{Everybody at Tokyo}

\section{from a Correspondent}

The International Congress of Genetics, in Asia for the first time in its long history, held its twelfth meeting in Tokyo from August 19-28. But the hospitality of the Japanese hosts was so overwhelming, the delights of Tokyo so demanding, the congress itself so enormous, that it is not yet possible to attempt an objective appraisal of its usefulness. There were more than 1,700 registrations; 980 papers were offered and 708 actually given; there were 21 invited lectures and 130 presentations in small symposia. Crow (Madison) characteristically noted that these totalled 323 hours of talk. But every paper began at the appointed minute. Every morning between 9 and 9.30 the buses from the hotels in which it was necessary to house so many converged on the conference hub, and every evening at 5.30 they fanned out again.

The proceedings began with a gracious address of welcome by HIH Crown Prince Akihito. Mornings were devoted to contributed papers, afternoons to invited lectures and to small symposia. The evening sessions contained the ideas, the new work and the most lively of discussions. Because there were as many as fourteen going on at once, however, the people best fitted to comment on a given paper were often elsewhere. In the afternoons came the reviews of particular fields of activity, and there were outstanding discussions by Sheppard (Liverpool) pleading the value of a more ecological approsch to evolutionary genetic problems, Lejeune (Paris) on human cytogenetics and Dubinin (Moscow) on classification of genetic potential damage. The small symposia concentrated on specific problems, in which it was possible to put into perspective work on related topics from different laboratories, and here formality prevailed. In the evenings came the receptions, the film shows, and a Haldane Memorial session, from which all left the hall very aware of the debt owed to him.

There were large gaps where major topics were not covered. There was little that was really new. It was fitting that there should be some concentration on genetic effects of radiation, to which 12 sessions and an invited lecture were devoted. After all, the hosts are still, 23 years later, tracing the effects of Hiroshima and Nagasaki on children then unborn. It was equally fitting that much attention and most of the demonstrations were devoted to the genetics of Asian plants and 